\title{
VULNERABILIDADE DE MULHERES USUÁRIAS DE DROGAS AO HIV/AIDS EM UMA PERSPECTIVA DE GÊNERO
}

\author{
Vulnerability of Women User of Drugs to \\ the HIV/ AIDS in a Gender Perspective \\ Vulnerabilidad de Mujeres Usuarias de Drogas \\ al VIH/ SIDA en una Perspectiva de Género
}

Jeane Freitas de Oliveira ${ }^{1}$

Mirian Santos Paiva

\begin{abstract}
Resumo
Este artigo discute a vulnerabilidade de mulheres usuárias de drogas à infecção pelo HIV/AIDS. Trata de estudo qualitativo cujos dados foram apreendidos pela observação de campo e entrevista com dezoito mulheres, durante atividades de extensão direcionadas a pessoas usuárias de drogas. A análise apontou condutas relacionadas às práticas sexuais e ao uso de drogas, interligadas e norteadas por construções sócio-culturais que ampliam a vulnerabilidade das usuárias à infecção pelo HIV. Independente do tipo de droga, modalidade e rede de uso, o consumo de drogas por mulheres e sua convivência com pessoas usuárias de drogas, em relacionamentos sexuais e afetivos, constituem situações de vulnerabilidade à infecção pelo HIV, com grau diferenciado nos níveis individual e social. Essas situações estão permeadas por relações desiguais de gênero e poder e apontam para necessidade de estudos e de intervenção numa abordagem de gênero contemplando pessoas usuárias de drogas, em particular as do sexo feminino.
\end{abstract}

Palavras-chave: Mulheres. Drogas llícitas. Vulnerabilidade. Síndrome de Imunodeficiência Adquirida. Identidade de Gênero.

Abstract

This paper discusses the vulnerability of women who are drug addicts in getting infected by the HIV/AIDS. It is a qualitative study whose data were collected by field observation plus interview with eighteen women, during extra activities for drug addict people. The analysis presented conducts related to sexual behaviors and to use of drugs, connected by social and cultural constructions which increase the vulnerability to HIV infection. Regardless the kind of drug, way or net use, the drug addiction or even the continuous interaction with people who use drugs, whether in sexual or in emotional relationships, can be considered situations of vulnerability to HIV infection in dissimilar degrees over the individual and social levels. These situations are filled in unequal gender and powerfulness relations, indicating the necessity of studies and a kind of intervention that addresses to the gender matter, beholding drug addict people, particularly female.

Keywords: Women. Street Drugs. Vulnerability. Acquired Immunodeficiency Syndrome. Gender Identity.

\section{Resumen}

Este artículo discute la vulnerabilidad a la infección por al VIH/Sida de mujeres usuarias de drogas. Trátase de un estudio cualitativo cuyos datos fueron captados por la observación de campo y entrevista con dieciocho mujeres, durante actividades de extensión con personas usuarias de drogas. El análisis apuntó conductas relacionadas a prácticas sexuales y uso de drogas, interrelacionadas y norteadas por construcciones socioculturales que amplían la vulnerabilidad de las usuarias al VIH. Independiente del tipo, modalidad y red de uso, el consumo de drogas por mujeres y su convivencia con personas usuarias de drogas, en relacionamientos sexuales y afectivos, constituyen situaciones de vulnerabilidad al VIH, con grado diferenciado en los niveles individual, social y político. Esas situaciones están permeadas por relaciones desiguales de género y poder y apuntan para la necesidad de estudios y de intervención en un abordaje de género contemplando personas usuarias de drogas, particularmente las del sexo femenino.

Palabras clave: Mujeres. Drogas llícitas. Vulnerabilidad. Síndrome de Inmunodeficiencia Adquirida. Identidad de Gênero. 


\section{INTRODUÇÃO}

A noção de vulnerabilidade na saúde surge como uma forma de compreender o processo de exclusão social como sustentáculo da disseminação do HIV e da expansão da AIDS. Nesta perspectiva, fornece elementos para avaliar objetivamente as diferentes chances que todo e qualquer indivíduo tem de se contaminar pelo vírus HIV. Estas chances estão imersas em um conjunto de características de ordem individual, social, cultural, política que estabelecem normas e condutas do cotidiano, julgadas relevantes para a maior exposição ou menor chance de proteção diante do problema'.

A análise da vulnerabilidade tem como propósito particularizar as diferentes situações de indivíduos e/ou grupos para um determinado agravo, baseando-se em três planos analíticos: individual, social e programático. A dimensão individual parte do princípio de que todas as pessoas são vulneráveis a um determinado agravo de saúde e envolve, principalmente, aspectos comportamentais, mas também cognitivos. Os comportamentos estão diretamente relacionados com o grau e a qualidade da informação de que as pessoas dispõem e a capacidade de incorporar esta informação e transformá-la em atitudes e práticas preventivas para determinado problema ${ }^{1}$.

A dimensão social diz respeito à avaliação de coletividades $\mathrm{e}$ enfoca fatores contextuais que definem e constrangem a vulnerabilidade individual, permitindo compreender comportamentos e práticas que se relacionam à exposição dos indivíduos à infecção. Nesta dimensão, consideram-se aspectos relacionados com: as estruturas jurídica e política e as diretrizes governamentais dos países; as relações de gênero, de geração e raciais; as atitudes diante da sexualidade; as crenças religiosas; a pobreza; o acesso aos meios de comunicação, escolarização, dentre outras. A dimensão programática, por sua vez, refere-se ao desenvolvimento de aç̃̃es institucionais, especialmente as de saúde, educação, bem-estar social e cultura, as quais atuam como elementos que reproduzem e aprofundam as condições socialmente dadas da vulnerabilidade ${ }^{1,2}$.

A noção de vulnerabilidade mostra-se bastante útil para o entendimento da disseminação da AIDS no segmento feminino, uma vez que esta ocorre no entrecruzamento de comportamentos e vivências individuais e subjetivas ligadas a questões como sexualidade, fidelidade, preconceitos, liberdade e morte, permeadas por relações desiguais de gênero e de poder ${ }^{3}$. Destacase neste entrelaçamento a vulnerabilidade feminina decorrente da expansão do consumo de drogas entre as mulheres.

Este artigo discute a vulnerabilidade de mulheres usuárias de drogas ao HIV a partir de condutas por elas adotadas para o consumo de drogas. As situações apresentadas estão mais diretamente relacionadas com as dimensões individuais e sociais da noção de vulnerabilidade. 0 estudo parte do pressuposto de que as condutas praticadas por mulheres que consomem álcool e outras drogas estão norteadas por construções sócio-culturais que estruturam as relações sociais e determinam papéis e comportamentos para homens e mulheres em distintas sociedades, constituindo, assim, situaçõ̃es de vulnerabilidade para grupos e pessoas inseridas num mesmo contexto sócio, econômico e cultural.

\section{METODOLOGIA}

Trata-se, de um estudo exploratório, de abordagem qualitativa, que responde a indagações de cunho particular, visto que corresponde a um espaço profundo das relações, dos processos e dos fenômenos que não podem ser reduzidos à operacionalização de variáveis ${ }^{4}$.

0 lócus de investigação constituiu-se em duas comunidades caracterizadas pelo alto consumo e tráfico de drogas do município de Salvador-BA, nas quais foram identificadas mulheres usuárias de drogas que, de acordo com os critérios de seleção, constituíram sujeitos desse estudo. As comunidades tinham características sociais e econômicas similares. A inserção nas comunidades ocorreu mediante participação ativa num projeto de extensão (Projeto Pontos Móveis -PPM) desenvolvido por um Programa de Redução de Danos de uma unidade especializada no estudo e na terapia de pessoas usuárias de drogas e seus familiares, caracterizada como setor de extensão permanente da Universidade Federal da Bahia. As ações, de cunho preventivo e educativo, eram realizadas semanalmente por uma equipe multidisciplinar composta por enfermeira, sociólogas, estudantes de medicina, enfermagem, psicologia e redutores de danos (usuários e/ou ex-usuários de drogas treinados por profissionais de saúde para atuarem de forma preventiva junto a outros usuários de drogas).

Todas as atividades do projeto estavam embasadas na política de Redução de Danos para o consumo de drogas. Tal política reconhece que as pessoas continuarão a utilizar substâncias psicoativas como sempre o fizeram ao longo de sua história e, a partir daí, busca minimizar as consequêências adversas decorrentes do consumo de tais substâncias para saúde sem, necessariamente, reduzir esse consum $0^{5}$. As ações do PPM não eram normatizadas, isto é, elas eram desenvolvidas com base em necessidades identificadas pelo(a)s profissionais em campo, assim como em solicitações apresentadas pelas pessoas atendidas com o objetivo de orientar, informar, encaminhar e encontrar formas de uso de drogas com menos danos para saúde individual e coletiva daquelas pessoas que não conseguiam e/ou não queriam parar de consumir drogas. De certa forma, as ações destinavamse a todas as pessoas que moravam na comunidade, embora a população alvo fosse de usuários de drogas.

Durante o período de um ano e seis meses foi realizada a observação de campo com registro em diário de campo. Foram observadas e registradas informações referentes às: características sócio-demográficas da população atendida e aos contextos sociais nos quais os participantes do projeto estavam inseridos, sempre com ênfase na população feminina; participação da população nas atividades de projeto; reações imediatas diante das orientações prestadas; informações sobre adoção ou não de condutas de redução de danos recomendadas. A partir das observações e de contatos mantidos com informantes-chave, partiuse para seleção e realização das entrevistas.

As entrevistadas foram selecionadas segundo os seguintes critérios: ter idade acima de 18 anos, não estar sob efeito de substâncias psicoativas durante a entrevista, ser moradora de uma das comunidades de atuação do projeto e participante do 
projeto; usar e/ou ter feito uso de uma ou mais drogas de forma habitual ou compulsiva por um período igual ou superior a seis meses. Foram entrevistadas dezoito mulheres identificadas pela técnica de bola de neve, na qual uma participante faz indicação de outra com base nos critérios préestabelecidos. A técnica de bola de neve (snowball sampling) consiste na identificação de uma ou mais integrantes da amostra; estas indicam outras que são qualificadas para o estudo, e assim por diante, até a obtenção do número suficiente que responda aos objetivos do estudo ${ }^{6}$. Esta modalidade de indicação atrelada à atuação nas atividades no projeto de extensão possibilitou a realização das entrevistas e, conseqüentemente, a coleta de informações.

As entrevistas foram guiadas por um roteiro contendo questões referentes aos dados de identificação, ao consumo de drogas adotado por elas e às situações enfrentadas diante dessa conduta. A concretização das entrevistas ocorreu após várias remarcações com cada participante, sendo realizadas individualmente, na casa de cada uma delas, fora do horário das atividades do projeto.

Cada entrevista teve duração média de quarenta minutos, e todas foram gravadas em fitas-cassete mediante autorização dos sujeitos, com assinatura do termo de consentimento livre e informado, de acordo com aspectos éticos previstos na Resolução 196/967 . 0 anonimato das participantes foi mantido, sendo atribuído a cada participante um pseudônimo escolhido por elas mesmas.

Este trabalho traz como recorte a análise de conteúdo das entrevistas, as quais foram transcritas na íntegra e submetidas às etapas da análise de conteúdo temática proposta por Bardin 7 , tendo como guia os objetivos da pesquisa. A organização dos dados revelou aspectos da vulnerabilidade relacionados ao uso de drogas e às práticas sexuais das entrevistadas que estão permeadas por construções sócioculturais que definem papéis de homens e de mulheres.

\section{ANÁLISE E DISCUSSÃO DOS DADOS}

\section{0 perfil das mulheres entrevistadas}

A idade das dezoito mulheres entrevistadas variou entre 18 e 46 anos. Algumas nasceram na comunidade onde moravam e outras residiam em uma das comunidades há pelo menos três anos. Com relação à cor, metade se classificou como da cor negra e a outra metade como da cor parda. Quanto à escolaridade, apenas uma das entrevistadas informou ter concluído $02^{\circ} \mathrm{grau}$, e as demais tinham $01^{\circ} \mathrm{grau}$ incompleto, sendo que uma estudou apenas até a $2^{\mathrm{a}}$ série, seis cursaram até a $4^{\mathrm{a}}$ série, cinco concluíram a $5^{\mathrm{a}}$ série, quatro, a $6^{\mathrm{a}}$ série, e uma, a $7^{\mathrm{a}}$ série.

A ocupação das entrevistadas foi assim referida: cinco exerciam atividades "do lar" sem nenhuma forma de remuneração; duas outras eram estudantes, duas eram garçonetes, quatro eram empregadas domésticas; três revelaram serem autônomas, desenvolvendo atividades como vendedora ambulante, baiana de acarajé e artesã; duas afirmaram exercerem a atividades como profissional do sexo. Das dezoito entrevistadas onze revelaram estarem desempregadas no momento da entrevista. Quatro delas informaram não ter filhos, sendo que, dessas, duas nunca engravidaram e as duas outras referiram ter engravidado, mas abortado. Duas outras se encontravam grávidas e as demais tinham entre um a quatro filhos.

Com relação à parceria sexual, quatro disseram ter parceiro fixo, sendo que duas estavam legalmente casadas e as outras duas mantinham união estável há mais de um ano. Nove revelaram ter parceiros múltiplos e/ou eventuais e manter relacionamento afetivo e sexual com um parceiro fixo. Cinco informaram ter parceiros múltiplos, sem parceria fixa, embora manifestassem esse desejo. Uma dessas cinco era homossexual.

Todas as entrevistadas moravam nas comunidades nas quais o projeto desenvolvia as atividades e participavam do referido projeto há pelo menos um ano, de forma intermitente. Algumas (três) nasceram na comunidade onde ainda moravam e as demais estavam morando em uma das comunidades há pelo menos três anos juntamente com pais, outros parentes e/ou companheiro. As características sócio-demográficas das entrevistadas estão compatíveis com os demais moradores das comunidades.

\section{Sobre a influência dos homens para o consumo de drogas}

As técnicas adotadas para produção dos dados revelaram a tendência, entre as usuárias de drogas, de manter relacionamentos afetivos e sexuais com homens, também, usuários de drogas. Esta tendência é demarcada em estudos nacionais e internacionais que abordam sobre o consumo de drogas envolvendo a população feminina. As entrevistadas apontam a convivência e a influência de parceiros usuários de drogas como motivações para início e manutenção do consumo de drogas.

Comecei a usar drogas quando tinha 13 anos. Conheci um rapaz, começamos a namorar, ele usava muita droga lá em nossa casa e aí usei e gostei (Lili Carabina, 31 anos).

... nenhum deles chegou a usar porque eu usava, mas eu já usei o crack porque meu namorado usava (Lia, 21 anos).

A possível influência de pessoas do sexo masculino sobre as mulheres para início e manutenção do consumo de drogas é consenso na literatura especializada. Há registro de mulheres que se tornam usuárias abusivas de drogas pelo fato de beberem para acompanhar os parceiros e, neste caso, tornam-se mais vulneráveis a patologias decorrentes da alta ingestão de álcool e a situações de violência sexual ${ }^{9}$. Admite-se que os homens sejam, geralmente, influenciados por pessoas do mesmo sexo ${ }^{10}$.

E, no caso do uso de drogas classificadas social e juridicamente como ilícitas, elas afirmam que os parceiros tornam-se os principais fornecedores, evitando, assim, que elas se exponham para compra das substâncias utilizadas. Esta atitude, a princípio, mostra-se como protetora para as mulheres pelo fato de reduzir e/ou evitar sua presença nas bocas de fumo, sua aparição para comunidade e, conseqüentemente, o enfrentamento de situações preconceituosas e de discriminação. Por outro lado, o discurso das entrevistadas salienta a propagação da hegemonia masculina manifestada pela dominação dos homens nas bocas de fumo e pela subordinação das mulheres até mesmo às drogas que eles adquirem e que 
disponibilizam para elas como usuárias. Salientam, também, que esta é uma conduta de autoproteção para os homens, pois em caso de eles serem presos pela policia, elas têm mais condições de articular meios para libertá-los.

$E$, se é ele que vai preso, sabe que a mulher estando fora da droga, fora do tráfico vai correr atrás para tirar ele de lá. Porque, normalmente, ele já tem uma entrada, já cumpriu uma pena, e para entrar na delegacia para falar com o poder, um delegado, um juiz, ele já é mal visto e você não. Primeiro, porque você é mulher, isso facilita, e depois pega o filho bota no braço, o sobrinho bota na mão e isso sensibiliza, é diferente, mas só vivendo para ver como é (Vera, 32 anos).

0 consumo de drogas ilegais entre as mulheres leva consigo uma carga emocional de desgosto e medo do público ${ }^{11}$. Carga esta que está relacionada com a consideração do consumo de drogas como um comportamento socialmente desviante ${ }^{11} \mathrm{e}$ com os papéis sociais e culturais destinados às mulheres, quais sejam: mãe, esposa e cuidadora da família. Nesta perspectiva, a mulher que adota o consumo de drogas está duplamente contrariando as normas sociais. Estas concepções de certo contribuem para o ocultamento do consumo de drogas por mulheres e, conseqüentemente, para vulnerabilidade destas a vários agravos sociais e de saúde, dentre eles a infecção pelo HIV ${ }^{13}$.

As entrevistadas reconhecem a existência de muito estigma e preconceito em torno do consumo de drogas até mesmo por parte de pessoas usuárias de drogas, mais especificamente, de homens. De acordo com relatos, estes preferem manter relacionamentos com mulheres não usuárias de drogas.

É muito difícil ser mulher e ficar usando drogas, porque para os homens não, é tudo normal. Eles que são homens, ninguém liga, mas nós, que somos moças, temos que ter um comportamento que mostre a eles que a gente um dia vai ser alguém, não uma pessoa sem valor; e sendo assim o homem não dá valor, eles nunca vão querer uma mulher errada para eles, por mais que sejam errados, nunca vão querer uma mulher errada (Inocência, 15 anos).

Acho que tem discriminação sim, porque tem homem que usa droga e não gosta que a mulher use. Tem homem que usa e diz assim: eu para ter uma mulher não quero ter mulher viciada, porque no dia que eu não tiver para dar a ela, ela vai e dá um corno em mim. Ele fica com medo (Meire, 32 anos).

A tendência de mulheres usuárias de drogas em manter relacionamentos com homens usuários de drogas e de homens usuários de drogas com mulheres não usuárias constitui mais uma forma de desigualdade entre os sexos vivenciada em nossa sociedade. Esta situação, sem dúvida, contribui para vulnerabilidade social e pessoal das mulheres ao HIV, tornando mais evidente a necessidade de compreender questões relacionadas com o uso de drogas, para a população em geral e, em especial, entre as mulheres.

\section{As drogas utilizadas pelas entrevistadas e as companhias de uso}

Há evidências de que o consumo de drogas envolve elementos relacionados à pessoa usuária, ao contexto social e cultural no qual a pessoa está inserida e faz o uso de drogas e, também, à substância em si. A interação entre esses elementos é bastante complexa e o desequilíbrio entre eles pode resultar no estado de dependência. Desta forma, uma pessoa pode apenas experimentar de uma ou várias drogas e não mais usálas ou só usá-las esporadicamente de forma social, ou ainda tornar-se usuária compulsiva de uma ou mais.

Moradoras de comunidades onde o consumo e tráfico de drogas se constituem em condutas normativas, as entrevistadas revelaram ter acesso a várias substâncias psicoativas e fazer consumo de forma compulsiva da maconha, cocaína, cracke álcool.

Eu fumo a massa, já fumei a pedra, hoje só de vez em quando é que fumo a pedra, mas a maconha eu fumo todos os dias. Não como sem fumar, só como depois que fumo, só tomo café se fumar, se não fumar fico com dor de cabeça, fico nervosa. Acho que já estou viciada, porque todo dia eu fumo (Gina, 25 anos).

... hoje uso maconha diariamente e uso também a cocaína e a pedra de vez em quando. Acho que estou viciada e já tenho o costume de todo dia. Mesmo sem trabalhar, uso todos os dias (Rose, 23 anos).

Todos os dias uso o crack, fumo duas ou três pedras e fumo a massa, que é a maconha (Josi, 21 anos).

0 uso de álcool isolado e/ou associado a uma determinada droga foi relatado como forma de intensificar os seus efeitos ou como droga substituta. Sua legalidade facilita o consumo social, sem perseguições, com muita oferta e com custo considerado baixo, pelas entrevistadas, em relação às demais drogas utilizadas.

0 uso social e/ou recreativo do álcool geralmente se dá em locais públicos juntamente com pessoas amigas, mas também com desconhecidos. Quando o uso é abusivo e praticado por mulheres, há uma tendência de o mesmo ser realizado em locais privados, freqüentemente no domicílio, como uma forma de ocultamento social.

Com relação ao uso abusivo do álcool por mulheres, há evidência de que a família procura esconder e negar o fato, encontrando meios para que o problema não saia do âmbito familiar com receios de estigmas e preconceitos sociais ${ }^{9}$. Esta situação retarda a busca de tratamento para agravos decorrentes do consumo da substância ao tempo que predispõe a usuária a situações de violências de ordem familiar. Portanto, constitui uma situação de vulnerabilidade para mulher determinada por construções sócio-culturais que estabelecem as identidades feminina e masculina.

No caso das drogas ilícitas, seu uso se dá, geralmente, em locais privados, independente da pessoa usuária ser do sexo masculino ou feminino, devido, sobretudo, a repressões e sanções legais. Neste estudo, esta tendência foi observada, assim como a limitação da rede de uso (pessoas com as quais se compartilha o uso de drogas) adotada, especialmente, pelas 
mulheres. As entrevistadas, na condição de usuárias de drogas ilegais, afirmaram ter uma rede de uso limitada ao parceiro, amigos e familiares como uma conduta de autoproteção contra atos de violência, principalmente abuso sexual, e discriminação por parte da comunidade e de outros usuários de drogas.

Uso sempre com meus amigos, meninos e meninas daqui e de outros lugares que conheço (Lene, 19 anos).

A cocaína, na maioria das vezes uso só. Sempre usei assim ou então com meu irmão ou com alguma colega minha. Mas não gosto de usar com pessoas que não conheço (Tânia, 27 anos).

Sempre uso só, nunca gostei de usar com outras pessoas porque tenho medo, ainda mais homem. Sei lá, fico com cisma de fazer alguma coisa comigo... e mulher... sei lá é porque eu nunca gostei mesmo (Lia, 21 anos).

A limitação da rede de uso de drogas para as mulheres por um lado reduz a vulnerabilidade das mesmas a determinados agravos, como, por exemplo, o abuso sexual. Por outro, aumenta o grau de vulnerabilidade para o HIV/AIDS, uma vez que, em geral, os homens usuários de drogas com os quais elas mantêm contato têm uma rede de uso de droga e sexual ampla e, na maioria das vezes, não adotam medidas de sexo seguro. A não-adoção de medidas de sexo seguro e a manutenção de relacionamentos sexuais com homens usuários de drogas colocam as mulheres usuárias de drogas, assim como as que não adotam tal conduta, em situação de vulnerabilidade para diversos agravos sociais e de saúde, dentre eles a infecção pelo HIV.

A AIDS mostra-se como um, dentre os muitos riscos, ao qual os(as) usuários(as) de drogas se expõem no dia-a-dia, na busca de testar e satisfazer sua fantasia de onipotência, de sobrepor-se à morte, de ser dono(a) da vida pelo lúdico que se outorga e dono da morte por não a temer ${ }^{13}$. Os motivos para esse jogo de cartas marcadas são variados e estão ligados à história de vida de cada um, porém com conseqüências trágicas para toda população, já que a disseminação do vírus se dá não apenas entre os pares.

\section{O uso do corpo:}

\section{a troca de sexo por drogas}

0 comportamento sexual se constitui num dos principais e mais complexos instrumentos da prevenção da epidemia da AIDS. No mundo das drogas, principalmente quando se trata da população feminina, a literatura aponta que em geral as mulheres tendem a valer-se do corpo como moeda de troca, enquanto os homens envolvem-se mais comumente com ações ligadas ao narcotráfico, assumindo, na maioria das vezes, a chefia de pontos de drogas, conhecidos popularmente como "boca de fumo".

Embora de forma discreta, há registros do envolvimento de mulheres em ações no narcotráfico, principalmente após o surgimento do crack, com destaque para as chamadas "mulas"14. Esta situação demarca mais uma vez as relações de poder entre os sexos, evidenciando desigualdades entre homens e mulheres.

Comentários e relatos de detalhes relacionados ao uso do copo como moeda de troca eram comuns entre as investigadas. Embora as entrevistadas negassem a adoção de tal prática e condenassem as mulheres que a adotam, reconheceram como sendo uma conduta comumente adotada por pessoas de seu grupo social e apontaram a associação desta conduta com a AIDS.

Agora também acho muito feio quem troca sexo por drogas, acho muito feio mesmo. Acho que a mulher nunca deve fazer isso, vender seu corpo. Tem muita gente que faz, eu conheço umas mesmo que fazem (Rose, 23 anos).

...tem muita gente que faz sexo pra conseguir a droga, mas eu nunca fiz isso, mas tem muitas mulheres que fazem isso. As mulheres fazem muito isso, trocar sexo por droga, tem mulheres que metem vergonha na outra (Gina, 25 anos).

Sei que tem gente que usa o corpo para se manter drogada. Eu acho que se você tem dinheiro, tem condições para comprar a droga tudo bem, mas vender seu corpo jamais. É ruim demais a pessoa vender seu corpo para se drogar. Conheço pessoas que fazem isso (Chica, 22 anos).

A associação da venda do corpo pela droga com o risco de contrair AIDS se dá pela revelação de que, geralmente, este tipo de transação ocorre sem adoção de medidas de sexo seguro, seja pelo efeito da droga no organismo, pela falta de acesso ao preservativo ou, ainda, pela dificuldade de incorporação dessa informação no comportamento sexual de um modo geral. Esta situação evidencia a influência de construções sociais e culturais em relação à sexualidade e à repressão sexual que permeia a educação das mulheres em nossa sociedade.

Embora os efeitos das drogas no organismo apareçam como um fator que dificulta a adoção do uso de preservativo, as entrevistadas revelaram não adotar medidas de sexo seguro, independe de estar ou não sob efeito das drogas. Para elas, a não-incorporação dessa medida preventiva ocorre muito mais por resistências pessoais e do parceiro, o que se coaduna com achados de outro estudo, onde as mulheres estudadas referem que, a despeito de valorizarem o preservativo como mecanismo de prevenção, encontram resistência dos parceiros no que concerne ao uso do mesmo ${ }^{16}$.

Mas, independente do efeito da droga, não uso preservativo (Vera, 32 anos).

Usando droga fica difícil de usar a camisinha, pelo menos pra mim, porque essa história de camisinha, ainda não me acostumei e, com as pessoas que eu estou acostumada a sair, que conheço, não uso camisinha ( Ana, 20anos).

Eu mesma não uso nada pra me prevenir independente de estar ou não usando a droga, mas acho que com o uso da droga não dá tempo de usar nada pra se prevenir, porque a gente fica afobado querendo logo e não dá tempo de botar a camisinha. Eu mesma quando uso droga não uso nada (Gina, 25 anos).

A resistência de muitos toxicômanos em não praticar sexo seguro pode ser explicada pela escassez ou ausência de preocupação com o outro, presente na personalidade do toxicômano, o qual procura priorizar o auto-erotismo no contato com o próprio corpo em detrimento do heteroerotismo ${ }^{14}$. A 
verdade é que a não-adoção do sexo seguro pelas usuárias de drogas, assim como a parceria com homens usuários de drogas, aumenta a vulnerabilidade das mulheres à infecção pelo HIV.

Neste estudo, a troca de sexo por droga não constitui, especificamente, prostituição, mas uma forma de negociação que está permeada por construções sócio-culturais que denotam o corpo da mulher como mercadoria, objeto de desejo. A relação entre drogas e prostituição não é um fenômeno recente, porém estudos realizados sobre esta problemática mostram que não é o uso de drogas que leva à prostituição, mas, uma vez iniciada esta prática, as mulheres procuram na droga um apoio, construindo assim um ciclo vicioso, onde uma situação concorre para a manutenção da outra ${ }^{15,17}$. A relação prostituição/drogas envolve temas presentes na sociedade que vão desde a sexualidade, 0 prazer, até a autonomia do ser humano sobre e com seu corpo, resultando assim em muita polêmica sobre o assunto.

\section{Os papéis de mãe e cuidadora e o consumo de drogas}

Tradicionalmente, o cuidado e a educação dos filhos é uma função feminina. Quando a mulher é uma usuária de drogas e negligencia este comportamento, ela passa a ser taxada, pela sociedade, como egoísta e irresponsável para com os filhos, se constituindo numa preocupação social.

A maternidade foi referida pelas entrevistadas e observada como conseqüência, não planejada, dos relacionamentos sexuais mantidos sem uso de preservativo e/ou de qualquer outro método contraceptivo. Na tentativa de atender aos padrões socialmente construídos de mãe e cuidadora dos filhos e da casa, as usuárias de drogas deste estudo revelaram abrir mão do convívio direto com os filhos como atitude de proteção, pois consideram que mantê-los distante do contexto sócio-ambiental onde elas vivem os afastará das drogas.

Outra conduta de proteção revelada por elas diz respeito à redução e/ou abstinência do consumo de determinadas substâncias, como, por exemplo, a cocaína e o crack, consideradas por elas drogas pesadas, durante parte ou por toda a gravidez, e, ainda, durante o período de aleitamento materno.

Parei um tempo de usar a cocaína por causa do meu neném, quando estava grávida (Ana, 21 anos).

Usava nos canos, mas deixei depois que engravidei da minha filha. Aí deixei mesmo de usar nos canos, isso já tem mais ou menos uns quinze anos (Meire, 32 anos).

A adoção de tais condutas - afastar-se dos filhos mantendoos longe de um ambiente onde o consumo e o tráfico de drogas é alto e reduzir e/ou abster-se do consumo de algumas drogas durante a gravidez e amamentação - parece colocá-las, de alguma forma, mais próximas dos papéis social e culturalmente estabelecidos para as mulheres - mãe, cuidadora, esposa.

Embora o cuidado com os filhos mostre-se mais associado às condições sócio-econômicas do que especificamente ao uso de drogas em $\mathrm{si}^{8}$, o fato de estar usando uma determinada droga de modo abusivo expõe a mulher a situações de discriminação e exclusão social, contribuindo assim para que o consumo se dê de forma oculta. Esse ocultamento, por sua vez, retarda qualquer tipo de tratamento específico e aumenta o risco para vários agravos sociais e de saúde.

A ação das drogas para saúde da mulher paulatinamente está sendo abordada na literatura brasileira especializada ${ }^{17-}$ 20. Porém, de um modo geral, a abordagem enfoca aspectos farmacológicos relacionados à substância e suas conseqüências para gravidez e para o feto, sem contextualizar as características da pessoa usuária e do contexto social e cultural no qual a pessoa está inserida.

\section{CONCLUSÕES}

Os dados apresentados revelam que, independente do tipo de droga usado, da modalidade e da rede de uso, o consumo de drogas por mulheres e a convivência destas com pessoa usuárias de drogas, com relacionamentos sexuais e afetivos, constituem importantes situações de vulnerabilidade para a infecção pelo HIV e AIDS, com grau diferenciado nos níveis individual, social e político. Essas situações estão permeadas por construções sociais e culturais que envolvem relações de desigualdades de gênero e de poder e que contribuem para a disseminação da AIDS na população em geral.

0 consumo de drogas assim como a prática sexual constitui condutas altamente complexas e abrangentes para as quais é difícil estabelecer medidas de intervenção de forma homogênea. Fica evidente que a relação entre droga e sexo facilita a exposição das pessoas à infecção pelo vírus da AIDS. Esta relação mostra-se bastante complexa uma vez que envolve questões de ordem individual e social, as quais são permeadas por sentimentos, normas, valores, crenças, religião, acesso a informações, resultando em condutas e atitudes. A complexidade parece ainda mais acentuada quando o grupo em foco faz parte de uma população culturalmente estigmatizada e discriminada como é o caso das mulheres, e mulheres que adotam um comportamento socialmente desviante.

Grupos populacionais de "homens" e de "mulheres" não constituem grupos homogêneos, devendo, assim, serem investigadas especificidades individuais e de grupos com vistas a uma assistência igualitária relacionada ao consumo de drogas. Fica demarcada a necessidade de novos estudos sobre a temática, que contemplem questões de gênero, no sentido de ampliar as possibilidades de intervenção e, consequentemente, de redução de vulnerabilidade. Este constitui, sem dúvidas, um novo e enorme desafio para profissionais da saúde, em especial para a Enfermagem, pelas características do trabalho que desenvolve no dia-a-dia com contatos diretos com indivíduos, famílias e comunidades. 


\section{Referências}

1. Ayres JRCM. 0 jovem que buscamos e o encontro que queremos ser. In: . HIV/AIDS, DST e abuso de drogas entre adolescentes: vulnerabilidade e avaliação de ações preventivas: São Paulo(SP): Ed eletrônica; 1996.

2. Ayres JRCM, Calazans GJ, Saletti Filho HC, França Júnior I. Risco, vulnerabilidade e práticas de prevenção e promoção da saúde. In: Campos GWS, Minayo MCS, Akerman M, Carvalho YMC, organizadores. Tratado de Saúde Coletiva. São Paulo(SP): Hucitec; 2006.

3. Villela W, Diniz S. A epidemia da AIDS entre as mulheres. São Paulo(SP): NEPAIDS/ CFSS; 1998.

4. Minayo MCS. 0 desafio do conhecimento: pesquisa qualitativa em saúde. São Paulo(SP): Hucitec; 2004.

5.0'hare P. Redução de danos: alguns princípios e a ação prática. In: Mesquita F, Bastos Fl. Drogas e AIDS: estratégias de redução de danos. São Paulo(SP): Hucitec; 1994.

6. Becker HS. Métodos de pesquisa em ciências sociais. São Paulo(SP): Hucitec, 1993.

7. Ministério da Saúde (BR). Conselho Nacional de Saúde.. Resolução CNS $n^{0} 196$, de 10 de outubro de 1996. Diretrizes e normas reguladoras de pesquisa envolvendo seres humanos. Inf Epidemio SUS 1996; 5 (2):14-41.

8. Bardin L. Análise de conteúdo. Lisboa(P0): Ed. 70; 1997.

9. Aquino MTC. A mulher e a droga: motivação para o uso, efeitos diferenciados, tratamento e possibilidades de prevenção. In: Baptista M, Inem C, organizadores. Toxicomania: uma abordagem multidisciplinar. Rio de Janeiro(RJ): NEPAD/UERJ/Sette Letras; 1997. p. 43-52

10. Substance Abuse and Mental Health Services Administration-SAMHSA. The National Cross-Sites Evaluation of High-Rise Youth Programs. Center for Substance Abuse Prevention. DHHS Publication. [on-line] 2002 [citado 10 maio 2005] Disponível em: <http://www. samhsa.gov.>

11. Romo N. Género y uso de drogas: la invisibilidad de las mujeres Humanitas, Humanidades Médicas 2004 [on-line] [citado 15 jan 2007]. Disponible em: <http://www.fundacionmhm.org/ Mono5/ Articulos/edicion 10.html>
12. Velho G. Desvio e divergência: uma crítica da patologia social. $7^{\text {a }}$ ed. Rio de Janeiro (RJ): Zahar; 1999.

13. Oliveira JF. Mulheres (con)vivendo com as drogas: vulnerabilidade e representações sobre a aids [dissertação de mestrado]. Salvador(BA): Escola de Enfermagem/UFB; 2001.

14. Bucher R. Drogas e drogadição no Brasil. Porto Alegre(RS): Artes Médicas; 1992.

15. Silva SL. Mulheres da luz: uma etnografia dos usos e preservação no uso do crack [dissertação de mestrado]. São Paulo (SP): Universidade de São Paulo; 2000.

16. Paiva EP, Motta MCS. A prevenção do HIV / AIDS segundo o olhar das mulheres: o caso do Grupo de Direitos Reprodutivos em Juiz de Fora- MG . Esc Anna Nery Rev Enferm. 2006; 10(2): 328-29

17. Hochgraf PB, Zilberman ML, Brasiliano S. A cocaína e as mulheres. In: Leite MC, Andrade AG, organizadores. Cocaína e crack: dos fundamentos ao tratamento.

Porto Alegre(RS): Artes Médicas Sul; 1999. p. 127-36.

18. Laranjeiras R, Ribeiro M. Drogas ilícitas e impacto sobre a saúde da mulher. In: Aldrighi JM, Buchalla CM, Cardoso MRA, organizadores. Epidemiologia dos agravos à saúde da mulher. São Paulo(SP): Atheneu; 2005.

19. Zilberman M. Uso de drogas entre mulheres. In: Baptista M, Cruz MS, Matias R, organizadores. Drogas e pós- modernidade: prazer, sofrimento e tabu. Rio de Janeiro(RJ): EdUERJ; 2003.v. 1. p. 175-85 20. Andrade AG, Abreu LN. Álcool e impacto sobre a saúde da mulher. In: Aldrighi JM, Buchalla CM, Cardoso MRA, organizadores. Epidemiologia dos agravos à saúde da mulher. São Paulo(SP): Atheneu; 2005.

\section{Agradecimento}

Aos integrantes do Projeto Pontos Móveis pelo companheirismo e ensinamentos valiosos durante as atividades. As colegas do Grupo de Estudo sobre Saúde da Mulher pelo incentivo para o desenvolvimento da pesquisa e compreensão das questões de gênero que norteiam as nossas relações cotidianas. À FAPESB pelo apoio financeiro, na modalidade de bolsa de doutorado, facilitando o desenvolvimento da pesquisa e estimulando publicações sobre a temática investigada. 